\title{
Krzysztof Kozłowski Wiersz o jesieni. O Frantzu François Ozona
}

\begin{abstract}
Kozłowski Krzysztof, Wiersz o jesieni. O Frantzu François Ozona [A Poem on Autumn. Frantz by François Ozon]. „Przestrzenie Teorii” 32. Poznań 2019, Adam Mickiewicz University Press, pp. 77-92. ISSN 1644-6763. DOI 10.14746/pt.2019.32.3.

The film Broken Lullaby ([1932] Ernst Lubitsch) and the novel L'Homme que j'ai tué ([1921, 1925, 1930] Maurice Rostand) are seen to be the main inspirations for Frantz (2016) by François Ozon. On the basis of methodology broadly understood as the concept of bringing into relief (Domański, 1992, 2002), this article aims to demonstrate the means by which the French director expanded upon the literary-film material, imbuing it with a totally singular meaning. Ozon's inventiveness did not limit itself to transformations typical for adaptations, but ventured towards feature film understood as a synthetic work of art that by exploiting the audiovisual properties of the medium itself, acts as a unifying force of poetry (Verlaine, Banville), music (Chopin, Debussy) and painting (Manet). The famous poem recited by the heroine, Ann, Chanson d'automne (Paul Verlaine), serves as the analytical starting point for the above. It is thus used as a pivot for the entire film, a veritable lodestar for guiding motifs, allowing important aspects of the film to be highlighted and consequently, bring its main theme to the fore.
\end{abstract}

KEYWORDS: Verlaine, music, painting, pacifism, love, forgiveness, untruth

Scenariusz Frantza (2016), którego autorem jest François Ozon (,avec la collaboration de Philippe Piazzo"), został zainspirowany mniej znanym filmem Ernsta Lubitscha z 1932 roku. Tak przynajmniej twierdzi francuski reżyser, dodając w poczuciu wdzięczności wobec niemiecko-amerykańskiego klasyka: „librement inspiré de Broken Lullaby d'Ernst Lubitsch, Universal Pictures".

Wszystkie te informacje pojawiaja się dopiero w napisach końcowych, zaraz po wymienieniu pełnej obsady filmu. Zdają się potwierdzać żywione w trakcie projekcji przekonanie, że historia Anny (Paula Beer) i Adriena Rivoire’a (Pierre Niney) została już kiedyś opowiedziana i że pojedyncze pomysły inscenizacyjne przypominaja sceny znane z Broken Lullaby lub też są ich parafraza. Dobrym przykładem swobodnej przeróbki z Lubitscha jest przybycie (po dłuższej przerwie spowodowanej bólem po stracie syna na I wojnie światowej) doktora Hansa Hoffmeistera (Ernst Stötzner) na spotkanie towarzyskie, w którym biora udział przede wszystkim ojcowie i krewni poległych żołnierzy. Innymi słowy, niemieccy patrioci, którzy zmuszeni sa stawić czoło przykrej prawdzie, że sami nieustannie zachęcali własne dzieci, by zgłaszały się do wojska i wyjeżdżały na front; prawdę tę dr Hans Hof- 
fmeister ${ }^{1}$ przypomni uczestnikom biesiad odbywajacych się w restauracji hotelowej w Quedlinburgu, czym - ku własnemu zaskoczeniu - zaskarbi sobie ich niekłamany szacunek. W filmie Lubitscha podkreśli to jeszcze nieobecny u Ozona uścisk dłoni doktora zainicjowany przez chodzacego o kulach młodego mężczyznę, wojennego rekonwalescenta, który - zgłaszając krytyczne uwagi - zawczasu zdążył subtelnie zaznaczyć swą obecność.

Broken Lullaby, inaczej niż Frantz, nie kryje jednak własnego źródła inspiracji, a przynajmniej nie przesuwa go do napisów końcowych. Przeciwnie, ujawnia je na początku, wraz z czołówką filmu: ,from the play The Man I Killed by Maurice Rostand and the adaptation by Reginald Berkeley".

Trzyaktowa sztuka z prologiem - oryginalny tytul, nadany jej przez Rostanda, syna poety i dramatopisarza Edmonda, brzmi: L'Homme que j'ai tué $e^{2}$ - miała premierę w paryskim Théâtre des Mathurins 12 stycznia $1930 \mathrm{roku}^{3}$. Za podstawę posłużyła Maurice’owi pacyfistyczna powieść własnego autorstwa, której pierwsze ujęcie ujrzało światło dzienne w 1921 roku w kolekcji nowości literackich ${ }^{4}$, a drugie - cztery lata później w Éditions Flammarion ${ }^{5}$. O tym, że powieść podlegała modyfikacjom i że losy głównego bohatera doczekały się kontynuacji, świadczy odautorska nota do wydania z 1934 roku $^{6}$, w którym Rostand, jako datę ukończenia ciagu dalszego, wskazuje przedział czasowy między wrześniem a grudniem 1930 roku. To ostatnie wydanie powieści dotyczy powojennych losów młodego Francuza, „zabójcy Hermanna von Holderlina”, jego żony Angéliki Kauffmann, a przede wszystkim ich syna, który - wybrawszy ostatecznie narodowość niemiecka - po I wojnie światowej, jako człowiek świetnie znający język i kulturę francuska, został ambasadorem w Paryżu, gdzie pełnił swą służbę aż do wybuchu kolejnego wielkiego konfliktu zbrojnego, i którego imię oraz nazwisko, Hermann von Holderlin, miało być znakiem sprzeciwu wobec przyszłej wojny. Krył się tu najważniejszy zamysł jego ojca, który - przyjeżdżając do Niemiec (w powieści Rostanda jest to „Oberwezel” [niem. Oberwesel], miasto leżące w Nadrenii-Palatynacie), pozostając tam na stałe i wyrzekając

${ }^{1}$ U Lubitscha: dr H. Holderlin.

${ }^{2}$ M. Rostand, L'Homme que j'ai tué. Pièce en 3 actes et un prologue, b.m. [Paris?] 1930.

${ }^{3} \mathrm{~W}$ Polsce po raz pierwszy wystawił ja 29 grudnia 1932 roku pt. Człowiek, którego zabiłem Instytut Reduty w Warszawie. Rok później, 1 czerwca, sztuka została pokazana przez Zespół Objazdowy Reduty. W obu wypadkach inscenizacje były reżyserowane przez zespół. Opiekę reżyserską sprawował bądź to sam Mieczysław Limanowski, bądź to do spółki z Juliuszem Osterwa, tłumaczenie i adaptację dramatu Rostanda przygotował Jerzy Zawieyski, a dekoracje wyszły spod ręki Kazimierza Pręczkowskiego. Zob. <http://www.encyklopediateatru.pl/przedstawienie/71743/czlowiek-ktorego-zabilem> [dostęp: 31.08.2019].

${ }^{4}$ M. Rostand, L'Homme que j'ai tué, „Les Euvres Libres” 1921, nr 3 (sept.), s. 169-215.

${ }^{5} \mathrm{M}$. Rostand, L'Homme que j'ai tué, Paris 1925.

${ }^{6}$ M. Rostand, L'Homme que j'ai tué, Paris 1934. 
się poniekąd swego dawanego życia - chciał w ten sposób zastapić zabitego i odpokutować swoją winę.

Ta skomplikowana i wielowątkowa historia uległa w filmie Broken Lullaby znacznemu uproszczeniu, nabrała charakteru wyraźnie religijnego. Oznacza to, że punktem wyjścia uczyniono uroczystości pierwszej rocznicy zawieszenia broni i podpisania pokoju, który nastał po I wojnie światowej: bicie dzwonu (czasami w równie bliskim planie jak w Matce Joannie od Aniotów Jerzego Kawalerowicza), katedra panoramowana pionowo w dół, więcej dzwonów... Kościelne wieże z zewnątrz. I jeszcze raz to samo. Wreszcie łuk tryumfalny, strzelające na wiwat armaty, kołyszące się mosiężne klosze, migawki z defilady i wnętrze szpitalnej sali. Radość miesza się z okrzykami przerażenia, bo nie wszyscy - a zwłaszcza ci, którzy wciąż pozostają trwale okaleczeni - zapomnieli o traumie przeżywanej w ostatnich latach. Mówiąc przesadnie, dla nich wojna się nie skończyła. Na jednym z wcześniejszych ujęć pokazujących defiladę oddział maszerujących wojsk widziany jest zza nóg stojących po bokach „gapiów”: niektórzy, pozbawieni kończyn i poruszający się o kulach, żadną miarą nie są w stanie przyswajać tego, co widzą i słysza, z entuzjazmem.

Akcja filmu Lubitscha zaczyna się 11 listopada 1919 roku i bardzo szybko przenosi się do wnętrza katedry, gdzie po odprawionej mszy młody mężczyzna, Paul Renard (Phillips Holmes), prosi wychodzącego z konfesjonału księdza o spowiedź. W jej trakcie wyznaje, że zabił młodego żołnierza niemieckiego, Waltera Holderlina (Tom Douglas), i że sytuacja była nietypowa, gdyż ten ostatni w ogóle się nie bronił. W retrospekcji widać bezradność zaskoczonej ofiary, książkę Beethovena (najprawdopodobniej wydanie jego listów) i kartkę papieru. Przerażony Paul ujmuje dłoń Waltera i pomaga mu podpisać niedokończony list. Walter umrze jednak, nim skreśli litere „r”. Po chwili namysłu Paul dopisuje ją własną ręką. Jest przerażony okolicznościami dokonanego czynu. Ma świadomość, że nic nie jest tak bolesne jak rana, która zadał samemu sobie. Wyszedłszy z katedry, postanawia wyruszyć do Niemiec i odnaleźć rodziców Waltera. Po przybyciu na miejsce nie potrafi się przemóc i wyznać, kim jest ani co zrobił. Przyjmuje fałszywą tożsamość, która podsuwają mu zbiegi okoliczności, dobroć gospodarzy i obawa przed ich zranieniem. Usilnie stara się wydostać z potrzasku. Przerażony rozmiarami kłamstw z litości, których się dopuścił, decyduje się odsłonić karty, ale ponosi porażkę, bo kiedy mówi kochającej go Elsie, co wydarzyło się w okopie na froncie, wszystko wraca w stare koleiny: jej zdaniem, chcąc odpokutować zbrodnię i zyskać spokój ducha, powinien dobrowolnie wypełnić lukę po Walterze, stać się niejako synem Holderlinów. Film Lubitscha zamyka scena wspólnego muzykowania Paula i Elsy, które wywołuje w doktorze i jego żonie najgłębsze wzruszenie, jako że i sam Walter był skrzypkiem. 
W filmie François Ozona zdarzenia te składają się zaledwie na połowę akcji, nawet na mniej, ponieważ Adrien (Paul) ani nie zostaje w Niemczech, ani nie poślubia Anny (Elsa). Ich historia raptownie się urywa. Anna rozstaje się z Adrienem i żegna go na dworcu w Quedlinburgu. Później nie odpowiada na jego listy. Te zaś, które rzekomo czyta Hansowi i Magdzie Hoffmeisterom, zmyśla na poczekaniu. Z pewnością nie robi tego lekką ręka (wyznanie poczynione księdzu w konfesjonale nie pozostawia co do tego wątpliwości), ale - przejmując na siebie część brzemienia Adriena - chce zapomnieć o tym, co zaszło. Nie Adrien (resp. Paul), lecz Anna (resp. Elsa, Angélica) staje się więc główną osobą dramatu. Ozon realizuje ów zamysł stopniowo. Tak kształtuje przejęte od Lubitscha i Rostanda tworzywo literackie (wątpliwe, by nie czytał powieści L'Homme que j’ai tué), że wprowadza do niego zupełnie nowe sensy. Świadome operowanie materią dowodzi oryginalności myślenia francuskiego reżysera. Cytowane słowa: „librement inspiré de Broken Lullaby d'Ernst Lubitsch" - skrywały to, co było najistotniejsze, a czego wydobycie zostało pozostawione widzowi, którego zainteresowanie filmem nie ograniczy się do niewymagającego śledzenia fabuły.

Najważniejszym obok Lubitscha (i Rostanda) źródłem inspiracji była dla Ozona literatura. Nie w znaczeniu adaptacji filmowej, lecz całkiem dosłownie: jako uobecnienie ${ }^{7}$. Co zrozumiałe, w filmie fabularnym to ostatnie musiało przybrać postać audiowizualna, zgodna z natura samego medium, w którym wszelka literatura staje się retoryką obrazu i dźwięku ${ }^{8}$.

I tak w funkcji zwornika całego filmu Ozon wykorzystał słynny wiersz Paula Verlaine'a, Chanson d'automne (Piosenka jesienna) z cyklu Poëmes saturniens (Wiersze spod znaku Saturna [1866]). Nie uczynił go jednak przedmiotem uwagi niespodziewanie, na odwrót - starannie przygotowywał grunt pod niewymuszoną deklamację, która zabrzmi nad mogiłą zmarłego narzeczonego Anny.

Po raz pierwszy wzmianka o - jeszcze bezimiennej - Piosence jesiennej pojawia się w ekspozycji filmu, kiedy to główna bohaterka, siedząc w towarzystwie rodziców Frantza (Anton von Lucke), Hansa i Magdy (Marie Gruber) Hoffmeisterów, wypytuje Adriena o relacje z jej zmarłym narzeczonym. Adrien nie jest się w stanie przełamać i wyznać całej prawdy, powoli,

${ }^{7}$ Jak wyjaśniał Juliusz Domański (Tekst jako uobecnienie. Szkic z dziejów myśli o piśmie $i$ książce, Kęty $2002^{2}$, s. 11), „[...] pismo i utwór literacki umożliwiają inną niż fizyczna obecność ludzi fizycznie nieobecnych czy to wskutek oddalenia przestrzennego, czy zwłaszcza wskutek biologicznej śmierci”. I dalej: „[...] w obszar refleksji nad uobecnieniem wchodzą zarówno bohaterowie, jak autorzy utworów, same zaś utwory mogą być przeznaczone do słuchania lub czytania [K.K.], a skala ich gatunkowej rozpiętości staje się znaczna" (tamże, s. 12).

${ }^{8}$ Zob. W. Faulstich, Estetyka filmu. Badania nad filmem science fiction „Wojna światów” (1953/1954) Byrona Haskina, przeł. M. Kasprzyk, K. Kozłowski, przedmową poprzedził i oprac. K. Kozłowski, Poznań 2017, s. 35-46 (,Biblioteka «Przestrzenie Teorii»”). 
acz nie bez narastającego oporu wewnętrznego (co znakomicie oddaje jego mimika i gestyka), brnie w coraz większe i bardziej kłopotliwe dla siebie kłamstwa. Odpowiadając na kolejne pytania, stwierdza, że poznał Frantza przed wojna. Nie protestuje, gdy rodzina bierze go za przyjaciela ich zmarłego syna, w jego łzach i kwiatach złożonych na grobie dopatrując się głęboko poruszających gestów. Nic dziwnego, że Anna czuje się w obowiązku wyznać, iż jesienią mieli się pobrać. Samo słowo „jesień” uruchamia przy tym ciąg nieuniknionych skojarzeń: przy milczącej postawie doktora Magda wyjaśni, że to właśnie jesień była ulubiona porą roku Frantza, Anna zaś doda tytułem komentarza: „Verlaine napisał wiersz o jesieni. Frantz nauczył mnie go”. „Po francusku” - dorzuci szybko pani Hoffmeister, aby pokazać stosunek niedoszłej synowej do tegoż języka ${ }^{9}$. Ta ostatnia informacja nie pozostanie bez echa dla formy uobecnienia wiersza Verlaine'a w filmie Ozona.

Dojdzie do niego przy grobie zmarłego, w sekwencji, która zostanie oddzielona od spotkania u Hoffmeisterów powrotem Adriena do hotelowego pokoju. Zaraz po wejściu główny bohater dostrzeże w lustrze - miast własnej - twarz Frantza. Nie ulega wattpliwości, że proces identyfikacji z ofiarą znaczacco się pogłębił i że kłamstwa wypowiedziane w domu rodzinnym zabitego jeszcze bardziej ożywiły napierajace od dawna wspomnienia.

Następnego dnia Anna i Adrien stana zgodnie przy grobie Frantza. Scena zaczyna się od krzyża z umieszczonym na tabliczce napisem: „hier ruht/ Gren. Frantz Hoffmeister/ Inf. Reg./ 12, 5.2.1895 - 15.9.1918”. Następujące ujęcia ukazują wazon z różami układanymi przez Annę i stojącego przy niej Adriena w szerszym planie; wolne tempo montażu i podwójne plany sprzyjają refleksyjnemu skupieniu. Anna wyjaśnia, że grób jest pusty i że Hans został pochowany we Francji w mogile zbiorowej, ,anonimowo, z innymi żołnierzami”. Mimo to, główna bohaterka przyznaje, iż ma czasem wrażenie, jakby Frantz miał jeszcze wrócić. Ponieważ Adrien zna całą prawdę, nie podejmuje tej myśli, wyraża jedynie swą wiarę w niewidoczną obecność cieni bliskich osób: „jestem pewien - powiada - że nas słyszy”. Anna przygląda mu się w milczeniu, po czym intonuje wiersz Verlaine'a:

Les sanglots longs

Des violons

De l'automne

Blessent mon coeur

D'une langueur

Monotone.
Łkanie bezsennej

Skrzypki jesiennej,

Sierocej,

Serce mi rani,

Grąży w otchłani

Niemocy.

${ }^{9}$ Najbardziej okazałe jest zmyślenie w formie barwnej retrospekcji, w której Adrien wraz z Frantzem zwiedza galerię obrazów w Luwrze. W dalszej partii filmu będzie to już nauka gry na skrzypcach: Adrien koryguje ułożenie dłoni ze smyczkiem i ramienia Frantza (nb. w filmie Ozona Adrien był przed wojną skrzypkiem Orkiestry Paryskiej). 
Tout suffocant

Et blême, quand

Sonne l'heure,

Je me souviens

Des jours anciens

Et je pleure;

Et je m'en vais

Au vent mauvais

Qui m'emporte

Deçà, delà,

Pareil à la

Feuille morte.
Drżący i siny,

- Gdy brzmia godziny

Tułacze, -

Wspomnieniem tonę

W czasy minione

I płaczę.

I idę smutnie

W wichr, co okrutnie

Mnie miecie

Swymi podmuchy,

Niby liść suchy

Po świecie ${ }^{10}$.

Tym, co rzuca na poezję Verlaine’a dodatkowy blask w warstwie audialnej filmu, jest szum wiatru w liściach. Słyszalny jest on wprawdzie od początku sceny, ale wyraźnie nasila się wraz z jej rozwojem. Zdaje się świetnie korespondować zwłaszcza z trzecią strofa, w której mowa jest o „złym wietrze" miotajacym człowiekiem to tu, to tam niczym suchym (zwiędłym, martwym) liściem (,feuille morte”). Zarówno Adrien, jak i Anna naznaczeni są śmiercią ${ }^{11}$, żyją w poczuciu winy i żalu.

${ }^{10}$ P. Verlaine, Piosenka jesienna, przeł. L. Staff, [w:] tegoż, Wybór poezji, oprac. A. Drzewicka, Warszawa i in. 1980, s. 14-16 („Biblioteka Narodowa”, seria II, nr 200). Mimo że Piosenka jesienna była bardzo często tłumaczona na język polski (,najbardziej znany jest przekład Staffa"), jak dotąd nie doczekała się wersji, która mogłaby się mierzyć z oryginałem (por. tamże, s. 16). Wśród tłumaczy byli m.in. Kazimiera Jeżewska i Tadeusz Miciński (zob. tamże, s. 16-17). Bardzo ciekawy pod względem poetyckim jest z całą pewnością przekład słynnego poety niemieckiego, Stefana Georgego (pt. Herbstlied) na jęz. niemiecki: „Seufzer gleiten/ Die saiten/ Des herbsts entlang/ Treffen mein herz/ Mit einem schmerz/ Dumpf und bang.// Beim glockenschlag/ Denk ich zag/ Und voll peinen/ An die zeit/ Die nun schon weit/ Und muss weinen.// Im bösen winde/ Geh ich und finde/ Keine statt.../ Treibe fort/ Bald da bald dort -/ Ein welkes blatt”. S. George, Gesamt-Ausgabe der Werke, t. 16: Zeitgenössische Dichter. Übertragungen, cz II: Verlaine, Mallarmé, Rimbaud, de Régnier, D’Annunzio, Rolicz-Lieder, Berlin 1929, s. 10.

${ }^{11}$ Podczas zakończonej pływaniem w jeziorze przechadzki, jaką Anna odbędzie z Adrienem - w warstwie muzycznej filmu, w kompozycji La promenade napisanej przez Philippe’a Rombie'ego wyraźnie słyszalne są motywy znane z filmów Lucchina Viscontiego - dowiemy się, że ulubionym poetą Anny był w początkach znajomości z Frantzem Rainer Maria Rilke. Zważywszy na czas akcji i młodość głównych bohaterów, nietrudno się domyślić, że fascynacja ta musiała być związana z tematyką śmierci, którą austriacki poeta tak sugestywnie wyraził w Sonetach do Orfeusza opublikowanych w 1922 roku. Sama wyprawa do krainy umarłych odbyła się jednak dużo wcześniej, o czym świadczy powstały jesienią 1904 roku wiersz pt. Orpheus, Eurydike, Hermes, który przyczynił się do narodzin dwudziestowiecznego orfizmu. Do sytuacji Anny - gdyby pójść tym tropem - dobrze pasowałyby następujące wersy: „Wie eine Frucht von Süssigkeit und Dunkel,/ so war sie voll von ihrem grossen Tode/ der also neu war, dass sie nichts begriff” (,Jak owoc pełen słodyczy i mroku,/ tak była pełna swojej 
Cmentarz-park, na którego terenie przebywaja, bardziej niż typowy niemiecki Kirchhoff przypomina modernistyczne jardines dolientes, jakkolwiek trzeba podkreślić, że stopienie topiki cmentarnej z ogrodową dokonało się przed wieloma laty. Jak pisał Jarosław Marek Rymkiewicz w Myślach różnych o ogrodach:

[...] za sprawą Goethego i Graya angielski park stał się podobny do cmentarza, a cmentarz do parku angielskiego, również [...] ogrody modernistów miały być podobne do cmentarzy. Ponieważ za sprawą Poussina i Delille'a symbole śmierci pojawiły się w idyllicznym krajobrazie, również [...] w idealnym pejzażu modernistów nie mogło takich symboli zabraknaćc. To dlatego Ernest Dowson w wierszu The Garden of Shadow, zapisując marzenie o miłości szczęśliwej, pokazał jednocześnie miłość idacca poprzez trawy cmentarza ${ }^{12}$.

Niemniej jednak uważne przyjrzenie się rozwojowi akcji ujawnia zastanawiający bieg myśli: otóż szum wiatru i szelest liści, na który Anna i Adrian zwrócą uwagę nieomal jednocześnie (naprzemiennie stosowane zbliżenia eksponują skupienie i bliskość obojga postaci), nie jest identyfikowany przez bohaterów ze złym wiatrem, co „mnie miecie/ swymi podmuchy”, lecz przywołuje całkiem nowe konotacje. Kiedy Adrien wyzna nieoczekiwanie: „zapomniałem o tym... O szumie wiatru w liściach”, Anna doda niezwłocznie: „To dlatego kocham wiosnę". I taka swoista „wiosenność” jesieni ${ }^{13}$, ściśle odpowiadająca porze roku, w której Adrien przybył do Quedlinburga, by się spotkać z rodziną Frantza i prosić o przebaczenie, będzie zgodna z intencją cytowanego wiersza. Bo też, jak zauważa Rymkiewicz, jesień nie była jeszcze dla Verlaine'a upragnioną pora roku, „tłem idylli - idylli [...] przez wiele wieków rozgrywającej się w krajobrazie wiosennym i zielonym" ${ }^{14}$, zapoczątkowanej przez Homera i Safonę $e^{15}$. Autor Chanson d'automne widział w jesieni czas smutku i łez ${ }^{16}$, ale tak jak dawni poeci i artyści marzył

wielkiej śmierci,/ tak nowej, że nie rozumiała nic"). R.M. Rilke, Orfeusz, Eurydyka, Hermes, [w:] tegoż, Poezje, wybrał, przeł. i posłowiem opatrzył M. Jastrun, Kraków 1987, s. 114-115.

${ }_{12}$ J.M. Rymkiewicz, Myśli różne o ogrodach, Warszawa 2010², s. 53-54.

${ }^{13}$ Jest to odwrócenie formuły „jesienność wiosny”, której użył Wiesław Juszczak w Studium wprowadzajacym do książki Malarstwo polskie. Modernizm. Zob. R. Okulicz-Kozaryn, Litwin wśród spadkobierców Króla-Ducha. Twórczość Čiurlionisa wobec Młodej Polski, Poznań 2007, s. 50.

14 J.M. Rymkiewicz, dz. cyt., s. 30.

15 Tamże, s. 31-32.

${ }^{16}$ Jak pisał o Piosence jesiennej Radosław Okulicz-Kozaryn (dz. cyt., s. 117), „drugi, równie znany wiersz francuskiego symbolisty, Piosenka jesienna z cyklu Smutne pejzaże, nie tyle postulował, ile wcielał zasadę muzyczną i kojarzył z nią porę jesieni. «Łkanie bezsennej skrzypki jesiennej, sierocej» zabrzmiało zatem przy kolebce prądu i towarzyszyło potem poezji nastrojowej jako temat niezliczonych wariacji w okresie jej dziwnego, bo napiętnowanego poczuciem klęski, wzrostu, podczas owej naznaczonej «jesiennością» wiosny”. - Pragnę w tym 
o wiecznej wiośnie, przynajmniej do chwili, gdy nie opublikował drugiego tomu wierszy, zatytułowanego Fêtes galantes (Zabawy miłosne) z 1869 roku. Zamykający go utwór Colloque sentimental (Rozmowa sentymentalna) stanowił w istocie świadectwo zwątpienia poety „[...] w możliwość ponowienia rokokowego modelu idylli. [...] w możliwość skonstruowania krajobrazu, który mógłby ukoić zadane przez czas lub miłość rany"17.

Piosenka jesienna skupia jak w soczewce najważniejsze cechy poezji Verlaine'a. Henri Peyre komentował:

[...] posłuszny swojemu temperamentowi Verlaine wolał, żeby krajobrazy, przedmioty ocierały się o niego, czasem wnikały głębiej, ale nie chciał ich interpretować ani dociekać, jakie kryją tajemnice. Charakterystyczna jest pod jego piórem częstotliwość zwrotów mówiących o niewiedzy, niepewności, rezygnacji z dowiadywania się [...]. Często nie chce organizować szczegółów w uporządkowany pejzaż - nie wskutek nieudolności, ponieważ jest autorem jednego z najlepiej skomponowanych pejzaży w niezwykle pięknym poemacie Bournemouth z tomu Miłość [...]. [...] Tylko nieliczni poeci francuscy umieli tak jak on wyrazić to uczucie czegoś przelotnego, niepokojącego, w czym zatraca się osobowość człowieka - co Eichendorff, Lenau czy impresjonista w rodzaju Mörikego wypowiadali po niemiecku ${ }^{18}$.

Obecność Verlaine'a w filmie Ozona nie ogranicza się do przywołania przez Annę jego nazwiska i zacytowania Piosenki jesiennej, z którą są powiazane sytuacje stricte filmowe. Sięga jeszcze głębiej, aczkolwiek obecność ta wyraża się bezpośrednio i pośrednio. Bezpośrednio, gdyż podczas wyprawy z Adrienem za miasto Anna wyjawia, że jej pierwsze spotkanie z Frantzem odbyło się „w księgarni, w czasie studiów” i że już wtedy powiedział, kto jest jego ulubionym poetą: Verlaine. Następne uobecnienie twórczości literackiej Verlaine'a dokonuje się pod postacia szacownie wydanego Choix de poésie, który Anna zamówiła, a otrzymała z rąk pani Hoffmeister, kiedy leżała chora w łóżku po tym, jak podjęła nieudaną próbę samobójczą. Na karcie tytułowej widoczne są nie tylko imię i nazwisko francuskiego poety, lecz także informacje o redaktorze edycji, autorze biografii słynnego impresjonisty: doktorze François Coppéem, poecie i akademiku. U spodu strony znajduje się jeszcze miejsce i rok wydania: „Paris 1896 [?]”. Swego rodzaju zapowiedzią pojawienia się $\mathrm{w}$ filmie tego tomu poezji jest scena na cmentarzu, w której Anna tak długo czyta na ławce książkę, aż nie zacznie padać i nie będzie musiała opuścić cmentarza z parasolem w ręku. Pośrednio, gdyż

miejscu serdecznie podziękować profesorowi Radosławowi Okulicz-Kozarynowi za niezwykle inspirująca „rozmowę o Verlainie i modernizmie”.

${ }^{17}$ Innymi słowy, „sentymentalna rozmowa jest [...] rozmową umarłych”. J.M. Rymkiewicz, dz. cyt., s. 76.

${ }^{18}$ H. Peyre, Co to jest symbolizm?, przeł. i posłowiem opatrzył M. Żurowski, Warszawa 1990, s. $124-125$. 
Ozon nawiązuje do Piosenki jesiennej także w scenach wzmagających się podmuchów wiatru. Raz dzieje się to noca przy grobie Frantza, w scenie wyznania całej prawdy, innym razem w chwili, gdy Anna - odprawiwszy Adriena do Francji na dworcu w Quedlinburgu - podlewa kwiatki rosnace na grobie narzeczonego. (Zaintrygowana intensywnością powiewu niemal zamiera w bezruchu i wyraźnie zaskoczona kieruje oczy ku wierzchołkom drzew - kamera panoramuje pionowo w górę, dopóki w kadrze nie znajdą się same gałęzie i liście). Kiedy indziej o nieoznaczonej porze dnia na cmentarzu. Główna bohaterka zajęta będzie wówczas anonimową lekturą. (Przykład ten łączy ze sobą uobecnienie pośrednie z bezpośrednim, jako że wcześniej antycypował tylko rychłe nadejście poczta Choix de poésie). Po raz przedostatni i ostatni poza miastem: na wzgórzu, gdzie Anna spacerowała w przeszłości z Frantzem, a niedawno z Adrienem, i nad jeziorem, z którego szczęśliwie wyłowi ją wędkujący nieopodal mężczyzna.

We wszystkich tych wypadkach nawiazania do wiersza Verlaine'a sa tyleż oczywiste, co zastanawiające. Konotują przy tym różne treści: z jednej strony utrzymujący się i pogłębiający stan melancholii Anny (bywa, że sceny skracają się do pojedynczych ujęć), z drugiej zaś obecność czegoś nieuchwytnego, przez co można rozumieć nadzieję na odrodzenie życia lub też - by odwołać się do dawnej topiki operowej - „głos z innego świata” 19 . Ten ostatni aspekt zagadnienia oznacza zawsze jakiś rodzaj manifestacji numinosum, a więc nadzwyczajnych fenomenów natury, wywołujących strach bądź „święte drżenie”. Jak wyjaśniał Reinhold Hammerstein,

są one doświadczane przez ludzi jako nadludzkie, boskie, demoniczne - rozumie się przez nie takie zjawiska świetlne, jak błyskawica czy nagłe nastanie ciemności, ewentualnie takie dźwiękowo-akustyczne zdarzenia, jak szum lub wycie wiatru, hucząca woda, szczekanie psa i szczęk łańcuchów. Wszystkie te odgłosy stanowia elementarna, pierwotną warstwę numinosum. I są one bezczasowe, to znaczy trwaja w poprzek epok i kultur w każdym człowieku jako egzystencjalne, a zarazem archetypowe wrażenia i sytuacje [Gegebenheit und Erinnerung], nie wyłączając „najbardziej postępowych” czasów ${ }^{20}$.

Pośrednie i bezpośrednie uobecnienia osoby i poezji Verlaine’a nie wyczerpują wszakże wszystkich zastosowanych we Frantzu technik uobecniających. Ozon, opierając się na tym, co stanowi o specyfice filmu fabularnego jako medium, wyszedł poza samą literaturę i wykorzystał do granic możliwości fakt, że film, jako retoryka obrazu i dźwięku, najczęściej skutecznie otwiera swe podwoje dla współistnienia i współdziałania sztuk. Jedyne

${ }^{19}$ R. Hammerstein, Die Stimme aus der anderen Welt. Über die Darstellung des Numinosen in der Oper von Monteverdi bis Mozart, Tutzing 1998.

${ }^{20}$ Tamże, s. 8. 
w swoim rodzaju, w wielu punktach - mimo oczywistych różnic - podobne do operowych. I tak Ozon, nie zapominając o naturze poezji Verlaine'a, a tym bardziej o napisanej przezeń Art poétique (1874) z tomu Jadis et Naguère (Ongiś i niedawno) z 1884 roku, w której francuski poeta postulował upodobnienie poezji do muzyki („Muzyki wszędzie, muzyki zawsze” [w. 29] ${ }^{21}$ ), poszerzył granice wiersza o (i) realnie brzmiąca w filmie muzykę (source music i score music) i (ii) zawężone do konkretnego obrazu malarstwo.

(i) Poszerzenie granic Pieśni jesiennej o muzykę, a nie chodzi w tym wypadku o zwyczajną w filmie fabularnym muzykę podmalowującą akcję, daje się uchwycić najlepiej we wspomnianej już scenie, w której Anna otrzymuje od Magdy poezje Verlaine’a. Po wyjściu pani Hoffmeister główna bohaterka leży w łóżku i czyta nowo zamówioną książkę. Jej uwagę przykuwa jednak coraz głośniej dochodząca $\mathrm{z}$ dołu dobrze znana melodia, dojazd kamery podkreśla tylko narastające na twarzy młodej bohaterki poruszenie. Anna zamyka książkę, odkłada ją na bok, wstaje z łóżka i zbiega po schodach. Przekonuje się, że w salonie odbywa się kameralny koncert: Frantz gra na skrzypcach, a Hans i Magda Hoffmeisterowie siedzą na sofie, słuchając jego interpretacji Lento con gran espressione cis-moll (WN 37) Fryderyka Chopina $^{22}$. Z czarno-białego obraz stał się tymczasem kolorowy. Magda, widząc Annę u wejścia, przykłada palec do ust: prosi ją w ten sposób, by nie przeszkadzała. Na twarzy Anny rysuje się radość, jakiej już nigdy więcej nie doświadczy. Szczęście trwa chwilę, bo kiedy grający Frantz odwraca się w stronę narzeczonej, okazuje się, że część czoła, szyja i fragment kołnierzyka od koszuli poplamione sa zeschłą krwią. Po cięciu montażowym gaśnie kolor, obraz wypełniają czerń i biel, a dźwięk odsuwanych zasłon i zbliżenie głowy Anny leżącej na poduszce (właśnie się przebudziła) dowodząjednego: to był tylko sen. Światło dzienne jest bezlitosne. Frantz nie żyje. Doktor Hoffmeister otwiera okno w sypialni Anny. Siada na krześle przy jej łóżku

${ }^{21}$ P. Verlaine, Sztuka poetycka, przeł. M. Jastrun, [w:] tegoż, dz. cyt., s. 136. Wolfgang Osthoff (Stefan George und „les deux musiques”, Stuttgart 1989, s. 2), pisząc o ściśle związanej z kręgiem symbolistów francuskich poezji Stefana Georgego, podkreślał zwłaszcza początkowy wers traktatu poetyckiego Verlaine'a: „De la musique avant toute chose” (Nade wszystko muzyki!"). Przypominał też o znaczeniu muzyki Richarda Wagnera dla Stéphane’a Mallarmégo, ale jednocześnie odnotowywał, że celem francuskiego poety nie była „wzbogacona poezja muzyka”, lecz „zawierająca muzykę i muzycznie ustrukturowana poezja”.

${ }^{22}$ Zdaniem Mieczysława Tomaszewskiego (Chopin. Człowiek, dzieło, rezonans, Kraków $2010^{2}$, s. 420 i 429) utwór ten, nazywany także nokturnem i zadedykowany „siostrze Ludwice dla wprawy” (1830), jest raczej lirykiem ulotnym, „sentymentalną kartką z albumu”, bo „faktura i nastrój nokturnu wypełnia[ja] jedynie ramy tej 65-taktowej miniatury, natomiast część środkową oddał kompozytor przypomnieniom i nawiązaniom natury sentymentalnej. [...] Otóż muzyka owej partii centralnej została w sposób naiwny i żartobliwy zarazem sklejona z reminiscencji z Koncertu pierwszego ( $f$-moll): takty $21-22$ i $25-26$ pochodzą z odmienionych nieco motywów finałowego Allegro vivace (1-14), a 23-24 i 27-28 ze wstępnego Maestosa (t. 41-42)”. 
i prosi ją by się przemogła i wróciła do życia: „Anno - mówi - kiedy straciliśmy Frantza, pocieszałaś nas. Pomogłaś nam przetrwać. Teraz nasza kolej. Musisz wstać. Wyjść z domu. Musisz żyć”. Po chwili widać, że Anna czuje się znacznie lepiej, siedzi przed domem i czyta książkę (trudno przypuścić, by mogło to być coś innego niż Verlaine).

Tak ścisłe powiązanie „nokturnu” Chopina z poezja Verlaine’a rozwiewa wątpliwości co do przypadkowości przyjętego w tych scenach zamysłu. Jest pewne, że kryje się tu klucz do literackologicznego myślenia Ozona ${ }^{23}$. I rzeczywiście, potwierdzaja to pozostałe wstawki muzyczne, w których wybija się Lento. Sprawa dotyczy jeszcze trzech sytuacji. Pierwsza z nich poprzedza zresztą właśnie omówioną. Chodzi mianowicie o scenę, w której Adrien - przy podjętym spontanicznie akompaniamencie Anny na pianinie gra na skrzypcach dla rodziców Frantza (source music). Do filmu wraca kolor, a rzeczy odzyskują swoje właściwości. Wówczas zestawianie wiersza o jesieni Verlaine'a z muzyką Chopina byłoby zapewne przedwczesne, teraz jest całkiem zrozumiałe. Trzecia wstawka - druga jest Frantz koncertujący we śnie Anny - towarzyszy głównej bohaterce, która po długiej przerwie pisze list do Adriena (score music). Co ciekawe, w tym wykonaniu Chopina linia skrzypiec łączy się z brzmieniem fortepianu. Adrien i Frantz zdają się wzajemnie przenikać: Anna czuje przecież miłosną więź z obydwoma mężczyznami. Czwarta wstawka Lento pojawia się w ostatnich ujęciach filmu, ale o tym można coś powiedzieć dopiero w podsumowaniu.

Poszerzenie granic wiersza Verlaine'a o muzykę jako odrębną sztukę, a nie tylko o muzycznie ustrukturowana poezję nie kończy się bynajmniej na Chopinie. W filmie Ozona podobną funkcję pełni wiersz La dernière Pensée de Weber (1845) Théodore'a de Banville'a z tomu Les stalactites (1846), który został umuzyczniony przez Claude’a Debussy'ego i którego tytuł w katalogu dzieł muzycznych tego ostatniego brzmi, jak następuje: Nuit d'étoiles. Jeśli uważnie wsłuchać się w dwie pierwsze strofy pieśni ${ }^{24}$,

${ }^{23} \mathrm{Na}$ temat pojęcia „literackologiczna struktura filmu fabularnego” zob. W. Faulstich, Estetyka filmu..., s. 96 i nn.

${ }^{24}$ Pieśń ta należy do najwcześniejszych utworów Debussy'ego. Przyjmuje się, że została umuzyczniona w 1876 roku. Jak pisał Stefan Jarociński (Debussy a impresjonizm i symbolizm, Kraków 1966, s. 136-137), „pierwsza wydana pieśń Debussy'ego, Nuit d'étoiles [...], jest o tyle interesująca, że w pierwszych pięciu akordach jej akompaniamentu występuje wyraźnie zarysowany motyw Melizandy. A że motyw ten łączy bliskie pokrewieństwo z czołowym motywem kantaty La Damoiselle élue (1888), jak również z początkiem De fleurs z Proses lyriques (1892-1893), oraz ponadto, że ten sam rysunek melodyczny, jaki tutaj kreślą słowa: «La sereine mélancolie...», powtórzy później Melizanda, otwierając trzecią scenę I aktu słowami: «Il fait sombre dans le jardin» [...], możemy śmiało powiedzieć, że w pieśni tej tkwia utajone jakby w zalążku charakterystyczne właściwości późniejszego stylu melodycznego Debussy'ego". 
stanie się jasne, że wiersz Verlaine’a i pieśń Banville’a-Debussy'ego łączy dużo więcej, niż wolno by się początkowo spodziewać. I to niezależnie od tego, że Verlaine, pisząc Fêtes galantes, wspierał się na prawie trzydzieści lat wcześniejszych wzorach, które ukształtował Banville ${ }^{25}$. Nawet jeśli kochankowie z Colloque sentimental „zgasłe mają oczy, zwiędłe wargi” („Leurs yeux sont morts et leurs lèvres sont molles") ${ }^{26}$, to i tak młody poeta złożył wspaniały hołd literacki starszemu koledze.

Wykonanie pieśni Banville'a-Debussy'ego odbędzie się we Francji, gdzie Anna pojedzie na wyraźne życzenie Hansa i Magdy Hoffmeisterów, aby odszukać i poślubić Adriena. Za scenerię koncertu posłuży zamek rodzinny Rivoire'ów. Trio wykonawców to Anna, Adrien i Fanny, narzeczona Adriena, o której istnieniu zarówno główna bohaterka, jak i widzowie dowiedza się tuż przed wieczornym występem. Nic dziwnego, że dla Anny będzie to wiadomość głęboko rozczarowująca, czego nie zdoła ukryć.

Dźwięki Nuit d'étoiles zaczną rozbrzmiewać już przy kolacji, co znakomicie podkreśla komplementarność obydwu scen. Muzyka sczepia je tak mocno, jak to możliwe, i czyni nierozerwalnymi. Koncertujące trio naznaczył w życiu i w sztuce ten sam okrutny los (Fanny straciła na wojnie młodszego brata, François), toteż słowa Banville'a i muzyka Debussy'ego splatają w jedną całość emocje ożywiające bohaterów, które Ozon niezwykle umiejętnie połączył z wymowna, pełną bólu i namiętności gra spojrzeń, nie zapominając ani na chwilę o słuchającej wykonawców publiczności:

Nuit d'étoiles, sous tes voiles,

Sous ta brise et tes parfums,

Triste lyre qui soupire,

Je rêve aux amours défunts.

La sereine Mélancolie

Vient éclore au fond de mon cœur,

Et j'entends l'âme de ma mie

Tressaillir dans le bois rêveur ${ }^{27}$.
Gwiaździsta noc, pod twoimi żaglami,

W twej bryzie i w twoich woniach, Smutna lira która wzdycha, Ja marzę o utraconych miłościach.

Pogodna melancholia

Rozkwita w głębi mego serca, I ja słyszę duszę mojej ukochanej Jak drży w śniącym borze.

przet. Beata Stefaniak

Niejakim zaskoczeniem może być fakt, że kiedy Anna przerwie grę i zakończy koncertowanie, bezpowrotnie utracone w jej oczach będą dwie

${ }^{25}$ Ponieważ Poëmes saturniens ukazały się w 1866 roku nakładem Lemerre’a, oficjalnego wydawcy parnasistów, trudno być zaskoczonym, że Banville przywitał je pochlebną recenzja. Zob. J.M. Rymkiewicz, dz. cyt., s. 70 i nn.

${ }^{26}$ Cyt. za: J.M. Rymkiewicz, dz. cyt., s. 76.

${ }^{27}$ Th. de Banville, Les Stalactites; Odelettes; Amethystes; Le Forgeron, Paris 1889, s. 86-87. 
miłości: do Frantza i do Adriena. Główna bohaterka wyzna to młodemu Francuzowi w swoim pokoju, gdzie skryje się, by opanować żałość. Adrien, nie rozumiejąc do końca, co się wydarzyło, będzie ją przekonywał do pozostania, choćby na jedną noc: „Nikt się nie obrazi. Wytłumaczę im”, ale po chwili, zapewne wspominając własny pobyt w domu Hoffmeisterów, zmieni zdanie: „Przepraszam. Masz rację, rób, jak uważasz”. Na dworcu w Saulieu, dokąd rano odwiezie ją automobilem, odczuje jednak dokładnie to samo, co Anna dnia poprzedniego: „amours défunts”. Podejmie jeszcze próbę odwrócenia biegu zdarzeń (ślub z Fanny był życzeniem jego matki, nieskorej do podejmowania Anny na zamku), aczkolwiek bez szans na powodzenie, bo główna bohaterka przetnie ewentualne starania krótkim „za późno”. Ich ostateczne pożegnanie rozegra się w milczeniu, jedynymi słowami będzie błogosławieństwo Adriena: „Bądź szczęśliwa, Anno”. Widziany z odjeżdżającego pociagu, stojący na peronie i znikający w kadrze Adrien mógłby teraz powtórzyć jak echo: „La sereine Mélancolie/ Vient éclore au fond de mon cœur,/ Et j'entends l'âme de ma mie/ Tressaillir dans le bois rêveur".

Mógłby, ale nie powtarza. I jest to zgodne z natura kompozycji Debussy'ego. Gdyż tak jak Verlaine lub Mallarmé dążyli do muzycznie ustrukturowanej poezji ${ }^{28}$, tak francuski kompozytor, autor Peleasa i Melizandy (1902), zmierzał do tego, by nawet w operze, a tym bardziej w pieśni, wyjść poza słowo, by porzucić w muzyce językowy charakter wypowiedzi artystycznej. Jak pisał Stefan Kunze: „muzyka jako medium tego, co niewyrażalne językowo, upodabnia się do odrzeczowionego języka w poezji symbolistów. Pelléas et Mélisande jest nie tylko «cieniem dramatu muzycznego» (Adorno), lecz także daje w śpiewie wyobrażenie o pozbawionym substancji języku"29.

(ii) Poszerzenie granic Pieśni jesiennej o malarstwo wiąże się z mało znanym do czasu nakręcenia filmu Ozona obrazem Le Suicidé Édouarda Maneta (namalowanym między rokiem 1877 a 1881) ${ }^{30}$. Obraz ten, o ubogiej kolorystyce, zasila obecnie prywatną kolekcję w Bazylei, nad którą opiekę

${ }^{28}$ W Kryzysie wiersza (Wariacje na pewien temat) czytamy: „Mówię: kwiat! i, zza niepamięci, gdzie mój głos odsyła wszelki zarys, muzycznie się wznosi, będąca czymś innym niż płatki znajome, myśl sama i upajająca, nieobecna w żadnym bukiecie”. S. Mallarmé, Wariacje na pewien temat, przeł. E.D. Żółkiewska, [w:] tegoż, Wybór poezji, redagował A. Ważyk, Warszawa 1980, s. 86.

${ }^{29}$ S. Kunze, Der Sprechgesang und das Unsagbare. Bemerkungen zu „Pelléas et Mélisande" von Debussy, [w:] Analysen. Beiträge zu einer Problemgeschichte des Komponierens. Festschrift für Hans Heinrich Eggebrecht zum 65. Geburtstag, hrsg. von W. Breig, R. Brinkmann und E. Budde, Stuttgart 1984, s. 359.

${ }^{30}$ Zob. A. Kilb, Diese Liebe beginnt mit einer Schusswunde, „Frankfurter Allgemeine Zeitung” 2016 (29 września); <https://www.faz.net/aktuell/feuilleton/kino/grosses-franzoesisches-kino-francois-ozons-frantz-14457832-p2.html?printPagedArticle=true\#pageIndex_1> [dostęp: 16.02.2020]. 
sprawuje Stiftung Sammlung E.G. Bührle. Jak dotąd nie udało się rozjaśnić nawet okoliczności jego powstania ${ }^{31}$.

We Frantzu występuje on jako lejtmotyw, łącznie aż pięć razy: dwukrotnie w słowie, trzykrotnie zaś wypełnia sobą mniej lub bardziej kompletnie przestrzeń kadrów. Za pierwszym razem mowa jest o nim w fałszywej reminiscencji Adriena, który własną fascynację tym płótnem przypisuje Frantzowi. Za drugim - w rozgrywającej się noca scenie na cmentarzu, kiedy Anna staje się oczekiwanym świadkiem wstrząsającego wyznania, jedynego w całym filmie aż tak gwałtownego. Pozostałe prezentacje dwakroć odbywają się w Luwrze, zawsze pod Śniadaniem na trawie (1863), i jeden raz w zamku rodzinnym Adriena: Anna zostaje zakwaterowana w pokoju, w którym oprócz obrazu Jezusa miłosiernego i krzyża wisi na ścianie kopia Le Suicidé Maneta. Co znamienne, główna bohaterka zwraca na nie baczna uwagę, jako że już w Luwrze, szukając Adriena (chwilę później odwiedzi Operę Paryską i wysłucha Szeherezady [1888] Nikołaja Rimskiego-Korsakowa), miała okazję wraz z licznie zgromadzoną publicznością podziwiać ten obraz w oryginale ${ }^{32}$.

${ }^{31}$ Już Linda Nochlin (Realizm, przeł. W. Juszczak, T. Przestępski, Warszawa 1974, s. 330) pisała, że „bardzo mało wiemy o szczegółach tematu tego obrazu”, został prawdopodobnie namalowany na aukcję wspierająca muzyka Alexandre’a Cabanera. „Tu, w Samobójstwie Maneta - dodawała amerykańska historyk sztuki - obraz ponownie postuluje jako wartości bezpośredniość ujęcia, prawdziwość, unikanie tego, co napuszone, melodramatyczne, zafałszowane, sztuczne w jakikolwiek sposób: jeżeli z opisu wyłania się jakieśs wzruszenie, jego źródłem jest zestawienie przypadkowej pozy, swobodnego, spontanicznego i szerokiego posługiwania się środkami technicznymi - krople krwi lśnią jak klejnoty czystego pigmentu na powierzchni płótna - z mrokiem i patosem ukrytym w sytuacji opisanej w sposób tak jawnie niedbały i prosty, w sposób wręcz niedelikatny i nieczuły" (tamże, s. 93).

${ }^{32}$ Anachronizmem (zapewne w pełni świadomym) ze strony francuskiego reżysera jest pokazywanie Samobójstwa i Śniadania na trawie w jednym miejscu i jednym czasie, jesienia 1919 roku, tak jakby istniał między nimi jakiś kontekstowy związek. Po pierwsze dlatego, że pierwszy z tych obrazów nigdy nie był pokazywany w Luwrze, po wtóre dlatego, że Śniadanie na trawie (sam malarz przez dłuższy czas używał wymownego tytułu La partie carrée) znalazło się tam dopiero w 1934 roku, kiedy to po śmierci dawnego właściciela, malarza, pisarza i kolekcjonera, Adolphe’a Étienne’a Auguste’a Moreau-Nélatona, przekazano je na życzenie zmarłego III Republice Francuskiej i umieszczono w Luwrze, gdzie pozostawało do czasu, aż nie trafiło do paryskiego Musée d’Orsay. Nawiasem mówiąc, Moreau-Nélaton nabył Śniadanie na trawie w 1898 roku od marszanda Paula Durand-Ruela. Ten ostatni zaś zakupił płótno od słynnego śpiewaka i kolekcjonera, Jean-Baptiste Faure’a, któremu - co wygląda na układ doskonale zamknięty - sam je sprzedał w 1878 roku; wcześniej pozostawało ono w pracowni artysty. Zob. B. Ahrens, Die Dejeuner-Malerei von Edouard Manet, Claude Monet und Pierre-Auguste Renoir. Untersuchung zur Darstellung von Mahlzeiten in der Zeit des französischen Impressionismus, Ludwigshafen am Rhein 2006, s. 59-60 [maszynopis]. Inna sprawa to semantyczny aspekt zabiegu Ozona. Czyżby chodziło wyłącznie o wyeksponowanie mniej znanego obrazu kosztem innego, który kojarzony jest niemal tak dobrze jak Mona Lisa? A może zamysł był dużo bardziej śmiały: wywyższyć Le Suicidé ponad słynne arcydzieło. 
W epilogu filmu Anna, przechodząc przez znane sobie sale paryskiego muzeum, ponownie zmierza w stronę płócien Maneta. Siada na ławce obok nieznajomego młodego mężczyzny, który - wyraźnie nią zainteresowany po niedługiej chwili pyta o to, czy podoba się jej ten obraz. Anna odpowiada zdecydowanie: „Tak. Sprawia, że chcę żyć”. Dojazd zoomem do zbliżenia twarzy głównej bohaterki i zmiana czerni i bieli na kolor raz jeszcze ożywiaja postaci oraz przedmioty. Ostatnim ujęciem filmu jest obraz Maneta, obrzeżony złotą ramą i wzmocniony życiodajnym blaskiem widocznym w oczach Anny, która wypełniła testament Frantza: „Obiecaj mi, Anno - pisał on w ostatnim liście - cokolwiek się ze mna stanie, będziesz nadal kochała życie i będziesz szczęśliwa" ${ }^{33}$.

W ujęciach tych bardzo ściśle łączą się obydwa skoncentrowane na uobecnieniu poszerzenia granic oddziaływania Piosenki jesiennej Verlaine'a. Oto bowiem obraz Maneta i muzyka Chopina, czwarta wstawka Lento con gran espressione cis-moll, tworzą nierozerwalną całość, pozasłowną i zgodna z estetyką symbolistycznej poezji. Sa jak Verlaine’owskie Pieśni bez słów (Romances sans paroles [1874]). Możliwe wyłącznie dzięki współistnieniu sztuk, które zapewnić mogło medium filmu jako filmu fabularnego. Dlatego też nic nadzwyczajnego $\mathrm{w}$ fakcie, że wiersz o jesieni francuskiego poety mógł stanowić doskonały punkt wyjścia do jedynego w swoim rodzaju eksperymentu. Skutecznego i - chyba nie trzeba tego dodawać - niedajacego się powtórzyć bez groźby popadnięcia w epigonizm.

\section{BIBLIOGRAFIA}

Ahrens B., Die Dejeuner-Malerei von Edouard Manet, Claude Monet und Pierre-Auguste Renoir. Untersuchung zur Darstellung von Mahlzeiten in der Zeit des französischen Impressionismus, Ludwigshafen am Rhein 2006 [maszynopis].

Banville Th. de, Les Stalactites; Odelettes; Amethystes; Le Forgeron, Paris 1889.

Bildanalysen: Gemälde, Fotos, Werbebilder, hrsg. von W. Faulstich, Bardowick 2010.

Domański J., Tekst jako uobecnienie. Szkic z dziejów myśli o piśmie i ksiażce, Kęty $2002^{2}$.

Eliot T.S., Od Poego do Valéry'ego, [w:] tegoż, Szkice krytyczne, wybrała, przełożyła

i wstępem opatrzyła M. Niemojowska, Warszawa 1972, s. 105-126.

Elsaesser Th., Das Weimarer Kino - aufgeklärt und doppelbödig, Berlin 1999.

Faulstich W., Estetyka filmu. Badania nad filmem science fiction „Wojna światów”

(1953/1954) Byrona Haskina, przeł. M. Kasprzyk, K. Kozłowski, przedmowa poprzedził i oprac. K. Kozłowski, Poznań 2017 („Biblioteka «Przestrzenie Teorii»”).

Faulstich W., Filmgeschichte, Paderborn 2005.

${ }^{33}$ Cień na to wypełnienie rzuca jedynie (a może: aż?) brzemię kłamstwa, które - nie chcąc zranić Hansa i Magdy Hoffmeisterów oraz chcąc uwolnić Adriena od nieznośnego poczucia winy - będzie musiała odtąd znosić sama. 
Friedrich H., Struktura nowoczesnej liryki. Od połowy XIX do połowy XX wieku, przeł. i opatrzyła wstępem E. Feliksiak, Warszawa 1978.

Gadamer H.-G., Poetica. Wybrane eseje, przeł. M. Łukasiewicz, Warszawa 2001 („Archiwum Humanistyki XX wieku").

George S., Gesamt-Ausgabe der Werke, t. 16: Zeitgenössische Dichter. Übertragungen, cz II: Verlaine, Mallarmé, Rimbaud, de Régnier, D’Annunzio, Rolicz-Lieder, Berlin 1929.

Hammerstein R., Die Stimme aus der anderen Welt. Über die Darstellung des Numinosen in der Oper von Monteverdi bis Mozart, Tutzing 1998.

Hirsbrunner Th., Debussy und seine Zeit, Laaber 1981 („Große Komponisten und ihre Zeit").

Jarociński S., Debussy a impresjonizm i symbolizm, Kraków 1966.

Juszczak W., Malarstwo polskie. Modernizm, Gdańsk $2005^{2}$.

Kilb A., Diese Liebe beginnt mit einer Schusswunde, „Frankfurter Allgemeine Zeitung” 2016 (29 września); <https://www.faz.net/aktuell/feuilleton/kino/grosses-franzoesisches-kino-francois-ozons-frantz-14457832-p2.html?printPagedArticle=true\#pageIndex_1> [dostęp: 16.02.2020].

Kunze S., Der Sprechgesang und das Unsagbare. Bemerkungen zu „Pelléas et Mélisande” von Debussy, [w:] Analysen. Beiträge zu einer Problemgeschichte des Komponierens. Festschrift für Hans Heinrich Eggebrecht zum 65. Geburtstag, hrsg. von W. Breig, R. Brinkmann und E. Budde, Stuttgart 1984.

Mallarmé S., Wybór poezji, redagował A. Ważyk, Warszawa 1980.

Nochlin L., Realizm, przeł. W. Juszczak, T. Przestępski, Warszawa 1974.

Okulicz-Kozaryn R., Litwin wśród spadkobierców Króla-Ducha. Twórczość Čiurlionisa wobec Młodej Polski, Poznań 2007.

Osthoff W., Stefan George und „les deux musiques”, Stuttgart 1989.

Peyre H., Co to jest symbolizm?, przeł. i posłowiem opatrzył M. Żurowski, Warszawa 1990.

Praz M., Zmysty, śmierć i diabeł w literaturze romantycznej, przeł. K. Żaboklicki, wstęp

M. Brahmer, Gdańsk $2010^{2}$ („Klasyka Światowej Humanistyki”).

Rilke R.M., Poezje, wybrał, przeł. i posłowiem opatrzył M. Jastrun, Kraków 1987.

Rostand M., L'Homme que j'ai tué, „Les Euvres Libres” 1921, nr 3 (sept.), s. 169-215.

Rostand M., L'Homme que j'ai tué, Paris 1925.

Rostand M., L'Homme que j'ai tué, Paris 1934.

Rostand M., L'Homme que j'ai tué. Pièce en 3 actes et un prologue, b.m. [Paris?] 1930.

Rymkiewicz J.M., Myśli różne o ogrodach, Warszawa $2010^{2}$.

Thibaudet A., Historia literatury francuskiej. Od Rewolucji Francuskiej do lat trzydziestych XX wieku, przeł. J. Guze, Warszawa 1997.

Tomaszewski M., Chopin. Człowiek, dzieło, rezonans, Kraków $2010^{2}$.

Valéry P., Estetyka stowa. Szkice, wybór A. Frybesowej, wstęp M. Żurowskiego, przeł. D. Eska, A. Frybesowa, Warszawa 1971.

Valéry P., Rzeczy przemilczane (Z pism o sztuce), wybór, przekład i noty J. Guze, Warszawa 1974.

Verlaine P., Wybór poezji, oprac. A. Drzewicka, Warszawa i in. 1980, „Biblioteka Narodowa", seria II, nr 200. 